Dokuz Eylül Üniversitesi-Mühendislik Fakültesi

Fen ve Mühendislik Dergisi

Cilt 19 Sayı 55.1 (Özel Sayı) Ocak 2017
Dokuz Eylul University-Faculty of Engineering Journal of Science and Engineering Volume 19 Issue 55.1. (Special Issue) January 2017

DOI: $10.21205 /$ deufmd.2017195528

\title{
Veri Dağıtım Servisi Tabanlı Sistemlerde Enine Kesen İlgiler için İlgiye Yönelik Programlama Yaklaşımı
}

\section{Ömer KÖKSAL ${ }^{1}$, Mirun AKYÜZ ${ }^{2}$}

${ }^{1}$ Wageningen Üniversitesi, Enformasyon Teknolojileri Bölümü, Wageningen, Hollanda 2 TOBB Üniversitesi, Mühendislik Fakültesi, Bilgisayar Mühendisliği Bölümü, Ankara

(Alınıș / Received: 14.06.2016, Kabul / Accepted: 12.08.2016, Online Yayınlanma / Published Online: 09.01.2017)

Anahtar Kelimeler İlgiye Yönelik Programlama, Dağıtık Sistemler, Veri Dağıtım Servisi
Özet: Dağıtık sistemlerin geliştirilmesinde, veri dağıtım servisi arakatmanı yaygın olarak kullanılmaktadır. Pek çok sektörde kullanımı hızla artan DDS arakatmanı, veri merkezli yayınla-abone ol tabanlı haberleşme mekanizması ve ön tanımlı servis kalitesi parametreleriyle ölçeklenebilir ve güçlü sistemler geliştirmek için idealdir. Ancak, veri dağıtım sistemindeki ilgilerin, tek bir modül içinde toplanamayacak şekilde dağıtık olması yeniden kullanılabilirlik, program bakımı ve yönetimi ve benzeri yazılım kalite faktörleri için problem oluşturmaktadır. Bu makalede, DDS tabanlı sistemlerdeki enine kesen ilgi problemlerine, ilgiye yönelik programlama yaklaşımı ile çözüm bulunması konusu incelenmiştir. Örnek çalışma kapsamında geliştirdiğimiz mini komuta kontrol sistemi üzerinde kodladığımız ilgilerin DDS tabanlı sistemlerin geliştirilmesinde ne gibi faydalar sağlayacağl, geliştirme ve test sürelerini nasıl kısaltacağı tartışılmıştır.

\section{Aspect Oriented Approach for Handling Cross-Cutting Concerns in Data Distribution Service Based Systems}

\begin{abstract}
Keywords
Aspect-Oriented

Software

Development,

Distributed

Systems,

Data Distribution

Service

Abstract: Data Distribution Service (DDS) is being widely used in developing distributed systems. The use of DDS middleware is being spread-out in many domains. With its data-centric publishsubscribe communication scheme and predefined Quality-ofService parameters, DDS is ideal to develop scalable and robust distributed systems. On the other hand, cross-cutting concerns in DDS are hard to localize within a single software module causing maintenance, management and reusability problems. In this paper, we have discussed handling cross-cutting concerns in DDS based systems with Aspect-Oriented Programming (AOP) approach. As the case study, having implemented a mini command and control system and developing sample aspects on it, we have discussed the benefits of using AOP approach and how it shortens the development and test phases in the development of DDS based systems.
\end{abstract}




\section{Giriş}

Günümüzde, dağıtık sistemlerin geliştirilmesinde, ana haberleşme çatısı olarak Veri Dağıtım Sistemi (Data Distribution Service - DDS) [13] kullanımı gittikçe yaygınlaşmaktadır. DDS, Object Management Grup (OMG) [12] tarafından yayınlanmakta olan bir standarttır. İlk sürüm 1.0, 2004 yllında yayınlanmıştır. Şu anki en son sürüm olan 1.4 ise 2015 yılında yayınlanmıştır.

DDS, daha önce OMG tarafindan tanımlanmış CORBA [22] arakatmanının aksine sunucu-istemci (client-server) mimarisi kullanmaz. Merkezi bir sunucu yerine, a $\breve{g}$ üzerinde dağıtık bir sistem haberleșmesini temel alır. "DDS - dağıtık sistem mimarisi" Şekil-1'de verilmiştir. $\mathrm{Bu}$ mimari ile ağ üzerindeki düğümlerden (node) biri ya da birkaçı çalışmıyor/hasarlı olsa bile, diğer düğümler üzerinde haberleşme gerçekleșebilir.

DDS, üzerinde veri iletişiminde yayınlaabone ol yazılım örüntüsü kullanan bir arakatmandır. Yayınla-abone ol örüntüsü başka arakatmanlar tarafından kullanılsa da (ör. HLA), DDS, servis kalitesi (Quality of Service - QoS) parametreleri sağlayan tek arakatman olması ile öne çıkmaktadır. QoS parametreleri ile verinin sadece nereden nereye gideceği değil, hangi servis kaliteleri ile gönderileceği ön-tanımlı olarak belirlenebilmektedir. DDS, düğümlerinde, pek çok yayıncı (publisher) ve abone (subscriber) birbirleri ile DDS konuları (topic) üzerinden haberleşirler. DDS mimarisinin sağladığı avantajlardan birisi de yayıncıların ve abonelerin birbirlerini tanımasına, fiziksel adreslerini bilmelerine gerek olmamasıdır. Hatta haberleșmenin gerçekleşmesi için, aynı anda hayatta olmalarına bile gerek yoktur.

Dağıtık yazılımlar, DDS arakatmanı ile geliştirilerek daha modüler, daha dayanıklı (robust) ve ölçeklenebilir bir şekilde geliştirilebilirler. Ancak, dağıtık yazılımlar, yapıları itibariyle pek çok "enine kesen ilgi" (cross-cutting concern) bulundururlar. Yüzlerce düğüm üzerinde çalışabilen dağıtık yazılımlar için enine kesen ilgiler milyonlarca satır kod üzerine dağılmıș olabilir. $\mathrm{Bu}$ durum, yazılımların bakımı, yönetimi ve geliştirilmesi açısından önemli bir problemdir.

$\mathrm{Bu}$ çalışmada, DDS tabanlı olarak geliștirilen dağıtık yazılımlardaki enine kesen ilgilerin oluşturduğu problemlerin "İlgiye Yönelik Programlama" (Aspect Oriented Programming) ile nasıl çözülebileceği konusu değerlendirilmiştir. Yazılım ve test mühendislerinin işlerini kolaylaştıracak, daha dayanıklı yazılım geliştirmeye yardımcl olacak ilgilere (aspect) odaklanılmıştır.

Örnek çalışma kapsamında, bir mini komuta kontrol yazılımı nesneye yönelik programlama ile geliştirildi. Daha sonra enine kesen ilgilerin yazılım üzerinde ne kadar dağıtık bir şekilde yer aldığı ve bunları yönetebilmek için ilgiye yönelik programlamanın nasıl kullanılabileceği gösterildi. Sadece nesneye yönelik programlama kullanıldığında, çok fazla kod değişikliği ile eklenebilecek bazı özelliklerin, ilgiye yönelik programlama ile minimum kodlama ile kolay bir şekilde yapılabileceği gösterildi.

Makalenin geri kalanı şu şekilde organize edildi: Bölüm 2, DDS hakkında artalan bilgileri verir. Örnek uygulama ve enine kesen ilgilerin belirlenmesi Bölüm 3'te anlatıldı. Bölüm 4 ilgiye yönelik programlama ile eklenen yeni özelliklerin detaylarını içerir. İlgili çalışmalar Bölüm 5'de, değerlendirmeler ve sonuç Bölüm 6'da yer almaktadır. 
Ö. Köksal ve M. Akyüz / Veri Dağıtım Servisi Tabanlı Sistemlerde Enine Kesen İlgiler İçin İlgiye Yönelik Programlama Yaklașımı

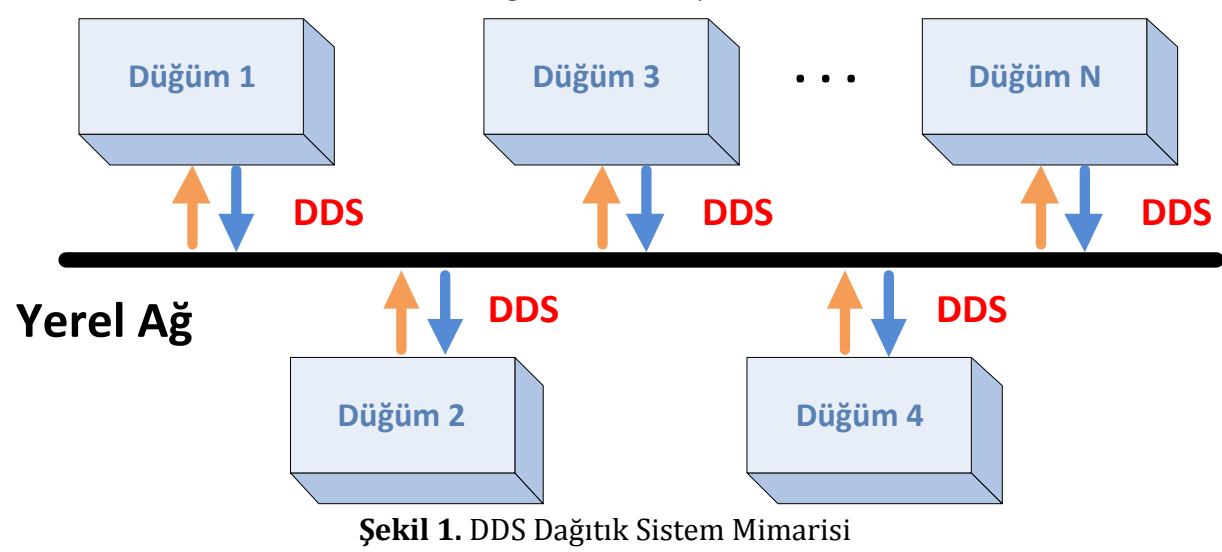

\section{Veri Dağıtım Servisi (DDS)}

Veri Dağıtım Servisi (Data Distribution Service - DDS) [13], özellikleri Object Management Group (OMG) tarafindan [12] standartlaștırılmış bir arakatman yazılımıdır. Dağıtık sistemlerde ana haberleşme çatısı olarak kullanılan DDS arakatmanının çalışma prensiplerini detaylı olarak anlatan pek çok referans bulunmaktadır [1, 2, 3, 8, 9, 10, 13]. Burada DDS'nin temel özelliklerinden bahsedilecektir.

\subsection{DDS Bileşenleri}

Bölge (domain): Bölge, birbiri ile iletişim kuracak uygulamaları bağlamak için kullanılan temel yapıdır. Tüm veri okuyucuları ve veri yazıcıları tanımlı bölge içerisinde iletişim kurabilirler. Dağıtık bir sistemde birden fazla bölge tanımlanıp verilerin sadece ilgili bölgelere gitmesi sağlanabilir.

Bölge İştirakçisi (domain participant): Bölge iștirakçisi, yazılım geliştiricinin varsayılan servis kalitesi (QoS) parametrelerini, ilgili bölgedeki tüm veri yazıcıları, okuyucuları, yayıncıları ve aboneleri için atamasını sağlar.

Veri Yazıcısı (data writer): Veri yazıcı, DDS veri bölgesindeki uygulamaların veri yayınlamasını sağlayan temel erişim noktasıdır.
Yayıncı (publisher): Yayıncı, veri yazıcıları gruplamak için kullanılır. Bir DDS bölge iștirakçisinin sadece bir yayıncısı olmasına rağmen bir yayıncının birden fazla veri yazıcısı olabilir.

Veri okuyucu (data reader): Veri okuyucu, DDS veri bölgesindeki uygulamaların veriyi almasını sağlayan temel erişim noktasıdır.

Abone (subscriber): Abone, veri okuyucuları gruplamak için kullanılır. Bir DDS bölge iștirakçi için sadece bir abone tanımlanabilirken bir abonenin birden fazla veri okuyucusu olabilir.

Konu (topic): Konu, yayıncı ile abone arasındaki iletişim noktasıdır. DDS sisteminde iletişimin sağlanabilmesi için yayıncının ve abonenin konusu ayn olmalıdır. Bu nedenle bir bölge içindeki konu isimleri eşsiz (unique) olarak belirlenmelidir

\subsection{DDS - Katmansal Mimari}

DDS, dağıtık yazılım geliştirme için uygun servisler ve özellikler sunmaktadır. Şekil 2'de verildiği gibi DDS, temel olarak iki ana katmandan oluşmaktadır:

- Veri tabanlı yayınla-abone ol (Data Centric Publish-Subscribe - DCPS) katmanı ve 


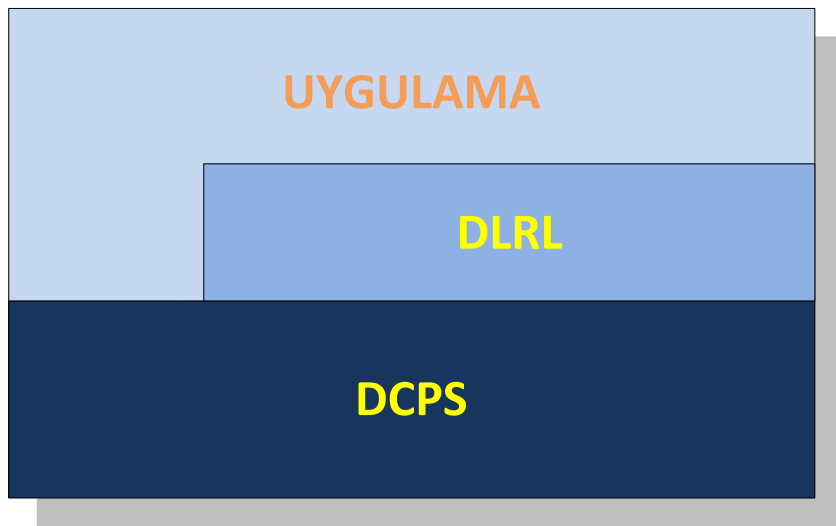

Şekil 2. DDS - Katmansal Mimari

- Yerel veri yeniden inșa (Data Local Reconstruction Layer - DLRL) katmanı.

DCPS, DDS'nin temel haberleşme katmanıdır. Yayınla-abone ol mimarisi ile çalışır. Uygulamaların içinde tanımlanan yayınclar ve aboneler birbirleri ile konular üzerinden haberleşirler. Haberleşmede kullanılan verinin özellikleri arayüz tanımlama dili (Interface Definition Language - IDL) [17] ile belirtilir. Her bir iștirakçi (participant) veri yayınlayabilir ya da istediği verilere abone olabilir. Yayıncllar, olay (event) şeklinde veri üretirler ve bu veriler aboneler tarafından tüketilir.

$\mathrm{Bu}$ mimarinin avantajı, yayıncl ve abonelerin birbirini tanımak zorunda olmamasıdır. Hatta yayıncı ve abone aynı anda hayatta olmak zorunda değildir. Bilmeleri gereken tek şey haberleştikleri konudaki verinin özellikleridir. Konu üzerinden gerçekleșen haberleșme bir gazete yazarı ile okuyucuları arasındaki haberleşme gibi düşünülebilir. Yazar, makalesini yazıp gazeteye gönderir ve makale yayınlanır. $\mathrm{Bu}$ haberleșmenin gerçekleșmesi için yazarın, aboneleri tanıması ve fiziksel yerlerini bilmesi gerekmez. Aynı durum gazete aboneleri için de geçerlidir.
DLRL'in temel görevi, nesneye yönelik programlamaya uygun olarak tasarlanmış bilgilerin, veri tabanlı yapıya çevrilmesi için (ve tersi akışlar için) çevirici görevi görmektir. DLRL katmanı isteğe bağlı olarak standarda eklenmiștir ve piyasadaki pek çok DDS sağlayıcı tarafından kullanılmamaktadır. DDS üzerinden veri iletişiminin nasıl gerçekleştiğini gösteren iletişim şeması Şekil 3'de [10] verilmiştir.

\subsection{DDS -Servis Kalitesi}

DDS, "Servis Kalitesi" (Quality of Service - QoS) isimli özel iletișim parametreleri kullanır. Yayınla - abone ol mimarisi kullanan başka arakatman yazılımları (ör. High Level Architecture - HLA) olmasına rağmen, DDS ön tanımlı QoS kullanımı ile dağıtık yazılım geliştirme sürecini kolaylaştırmakta ve hızlandırmaktadır.

QoS parametrelerine örnek olarak: yayınlama hizl (rate of publication), abone olma hızı (rate of subscription), verinin ne kadar süre ile geçerli olduğu (deadline), en son kaç adet verinin saklanacağl (history), gibi servis kaliteleri verilebilir. 


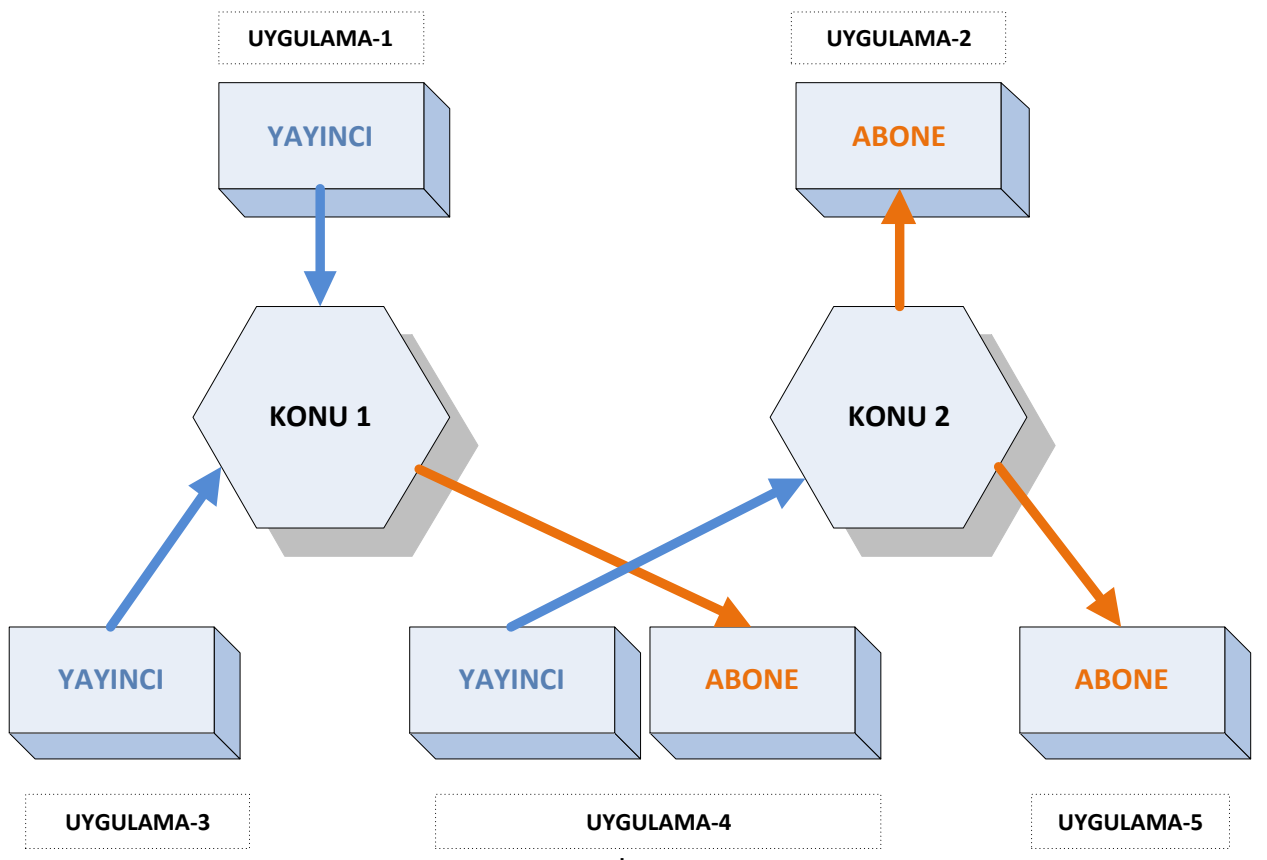

Şekil 3. DDS İletişim Şeması

Ayrıca, sürekli gönderilen veriler için continuous, sisteme sonradan katılan abonelere de gönderilmesi gerekli veriler için reliable, veriyi DDS veri tabanında saklamak için persistent, sıklıkla kullanilan QoS parametrelerindendir. Burada not edilmesi gereken önemli bir konu da, veri iletişimin gerçekleşebilmesi için yayıncl, abone ve konu için tanımlanan servis kalitelerinin uyumlu olmasıdır. Aksi halde veri iletişimi gerçekleşmez.

\section{3. Örnek Uygulama}

\subsection{C2S Yazılımı}

Makalede örnek uygulama olarak DDS tabanlı bir mini komuta kontrol sistemi (Command and Control System - C2S) geliştirildi. Enine kesen ilgilere odaklanabilmek için, C2S'nin tasarımı basit tutulmakla birlikte enine kesen ilgi problemlerini ve çözümleri gösterecek özellikler eklendi. Enine kesen ilgilerle neden karşılaşıldığı konusu üzerinde duruldu. C2S'nin geliștirilmesinde, OCI [20] tarafindan geliştirilen, açık kaynak kodlu OpenDDS yazılımı [4] kullanıldı. Kodlar, C++ ve Java dilleri kullanılarak nesneye yönelik programlama yaklaşımı ile yazıldı. Geliştirme, Eclipse [7] yazılım geliștirme aracı üzerinde gerçekleștirildi.

$\mathrm{Bu}$ amaçla gerçekleştirilen C2S, örnek olarak, sadece termal kamera ve lazer sensörlerinden gelen bilgileri alıp işleyerek bazı bilgileri kullanıcı arayüzünde gösterecek şekilde tasarlandı. Kullanıcının, arayüz üzerinden yaptığı değişiklikleri ve sensör ayarlarını DDS üzerinden sensörlere iletme özelliği eklendi. DDS tabanl C2S'nin iletişim altyapısı Şekil-4'te verilmiștir. Örnek çalıșma kapsamında iki sensör kullanılmış olmasına rağmen, tasarlanan sistem mimarisi daha büyük sistemlere kolaylıkla ölçeklenebilir şekilde geliştirilmiştir. Benzer şekilde, komuta kontrol altyapısı ve ilerideki bölümlerde açıklanacak olan ilgiler gelişmiş ve karmaşık sistemler için de aynen kullanılabilir olarak tasarlanmıştır. 

Programlama Yaklaşımı

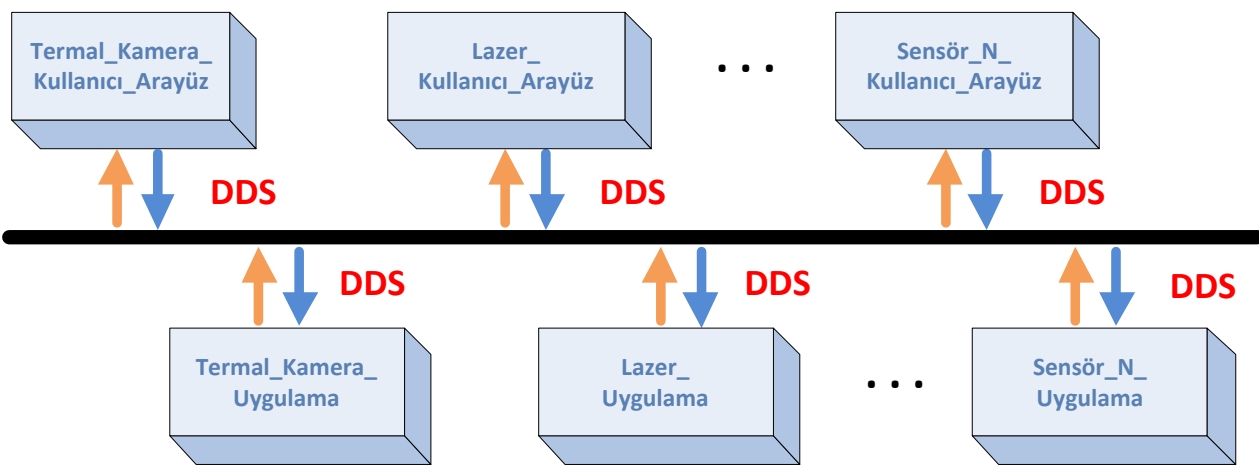

Şekil 4. Örnek Çalışma - C2S

3.2. Enine Kesen İlgilerin Belirlenmesi

Yukarıda belirtildiği gibi, örnek uygulama C2S nesneye yönelik programlama yaklaşımı geliştirilmiştir. C2S'deki uygulama ve kullanıcı arayüz sınıflarının benzer özellikler taşıyacağı açıktır. Örneğin, Şekil 4'te verilen her bir uygulama birimi tipik olarak veri doğrulama, veri işleme, veri kaydetme, sistem günlüğü tutma (logging) vb. fonksiyonları içerecektir. Bu ve benzeri fonksiyonların, yazılım içinde saçılmış (code scattering) ve dağıtık (code tangling) şekilde bulunması, yazılımın yönetilmesini ve idame ettirilmesini zorlaştırmaktadır. Örnek uygulamadaki enine kesen ilgiler, sadece nesneye yönelik programlamanın doğal yapısından kaynaklanmamakta, aynı zamanda kullanılan dağıtık mimari nedeniyle de yazılımda yer almaktadır. Örneğin, C2S'deki pek çok yayıncı ve abone için ayrı ayrı zamanlama ve iletişim kodları geliştirilmiştir. Bu ilgilerin tek bir yerde toplanması mümkün olmadığı için yazılım içinde dağıtık olarak yer almışlardır. Tanımlanan DDS servis kaliteleri için de durum benzerdir.

Enine kesen ilgiler problemleri için İlgiye Yönelik Programlama ile kolay ve hızlı çözümler üretilebilir [19]. Tanımlanan ilgiler ile yukarıda bahsedilen problemler için çözüm üretmek mümkündür. Örneğin, tüm sistem günlüğü tutma işlemlerinden önce başka bir fonksiyon çağırılmak isteniyorsa (ör. sabit diskte kalan yerin kontrol edilmesi gibi), yazılacak tek bir ilgi ile, bu değişiklik gerçekleştirilebilir.

Yukarıda bahsedilen enine kesen ilgiler, nesneye yönelik programlama yaklaşımı ile geliștirilen yazılımlarda tipik olarak bulunmaktadır. $\mathrm{Bu}$ makalede, DDS tabanlı sistemlerde karşımıza çıkan enine kesen ilgi problemleri üzerinde durulmuştur. Bu makalede, DDS tabanlı sistemlerin geliştirilmesinde, sıklıkla kullanılabilecek ilgilere yer verilmiştir:

DDS İzleme İlgileri (DDS Monitoring Concern): DDS tabanlı komuta kontrol sistemleri dağıtık mimaride tasarlanırlar ve yüzlerce düğüm içerebilirler. Tüm düğümlerde yayıncllar ve aboneler bulunabilir. Belli bir anda, tüm düğümlerdeki DDS bileșenlerinin (yayıncılar, aboneler, vs.) izlenmesi yazılım geliștirme ve test faaliyetlerinde önemli olduğu gibi yazılımın gerçek ortamda izlenmesi sirasında da önemlidir. Klasik yöntemlerle DDS bileşenlerinin izlenmesi çok zahmetli olabilir ve/veya büyük kod değişiklikleri gerektirebilir. Özellikle, kod satır sayısı 
arttıkça, yazılım geliştirme faaliyetleri sırasında aktif olan ancak haberleșemeyen yayıncı ve abonelerin tespiti büyük problem teșkil eder. Bu nedenle, ilgiye yönelik programlama ile geliştirilecek DDS izleme ilgileri, yazilımın geliștirilmesinde ve test edilmesinde önemli rol oynamaktadırlar.

Servis Kalitesi Uygulama İlgisi (EnforceQoS Control Concern): Bölüm 2'de belirtildiği gibi, DDS sistemlerinde haberleşmenin gerçekleşebilmesi için yayıncı ve abonenin aynı konu üzerinden konuşması ve bu üç DDS bileşenin de (yayıncl, abone ve konu) servis kalitelerinin uyumlu olması gereklidir. Servis kaliteleri uyumlu olmazsa, yayıncı ve abone hayatta olduğu halde, konu isimleri aynı bile olsa veri iletişimi gerçekleşmeyecektir.

QoS parametrelerinin izlenmesini ve değiștirilmesini sağlayacak ilgiler DDS tabanlı sistemlerin geliştirilmesinde önemlidir.

Dil Değişim İlgisi (Switching Language Concern): Bir komuta kontrol programı kullanıcı arayüzünde ya da veri kayıt/saklama işlemlerinde farklı dillerde çalışmayı desteklemelidir. Çoklu dil desteği sağlamak için özellikle kullanıcı arayüzündeki etiketlere, menülere ve diğer arayüz bileșenlerine erişerek farklı dil desteği eklenmelidir. Özellikle kalıt kod (legacy code) kullanıldığı durumlarda, enine kesen ilginin dağıtık olması sebebiyle bu özelliği eklemek büyük kod değişiklikleri, hatta yapısal değiş̧iklikler gerektirebilir. Ancak, bu amaçla geliştirilecek bir ilgi ile bu problem kolayca çözülebilir.

\section{4. İlgiye Yönelik Programlama}

Bölüm 3.1'de, örnek uygulama olarak geliştirilen C2S yazılımından ve Bölüm 3.2'de DDS tabanlı yazllımlardaki enine kesen ilgi problemlerinden bahsedilmişti. $\mathrm{Bu}$ bölümde ise belirlenen problemlere, ilgiye yönelik programlama ile nasıl çözüm bulunabileceğinden bahsedilecek ve geliștirilen ilgilerin detayları verilecektir.

İlgilerin kodlanmasında, açık kaynak kodlu AspectJ [5] kütüphanesi kullanılmıștır. AspectJ ve ilgiye yönelik programlama detayları için Aspect] programlama kılavuzuna bakılabilir [6].

\subsection{DDS İzleme İlgisi (DDS Monitoring Concern)}

Nesneye yönelik tasarım ile geliştirilmiş DDS tabanl bir sistemde, belli bir anda aktif olan DDS bileșenlerini ve/veya sistemdeki verileri izleyebilmek için DDS bölgesindeki (domain) tüm yayıncılar, aboneler ve veriler taranmalıdır. Sonradan yazılıma eklenen modüllerde de izleme ile ilgili metotların kodlanması gereklidir. Ancak, ilgiye yönelik programlama ile sistemde aktif olan tüm yayıncı ve aboneler izlenebildiği gibi, bunların istenilen özellikleri kolayca listelenebilir. Ayrıca, yeni yazılım modülleri eklendiğinde, izleme fonksiyonlarının eklenmesine gerek kalmaz.

Aşağıda, C2S için geliştirilen dört farklı izleme ilgisi anlatılmış ve ilgiye yönelik programlama ile geliştirilen AspectJ kodları verilmiştir. Bu dört ilgi, modüler olması açısından ayrı ayrı geliștirilmiştir. Ancak, proje gereksinimlerine göre, bu dört ilgi, tek bir ilgi altında da toplanabilir. 
Ö. Köksal ve M. Akyüz / Veri Dağıtım Servisi Tabanlı Sistemlerde Enine Kesen İlgiler İçin İlgiye Yönelik Programlama Yaklașımı

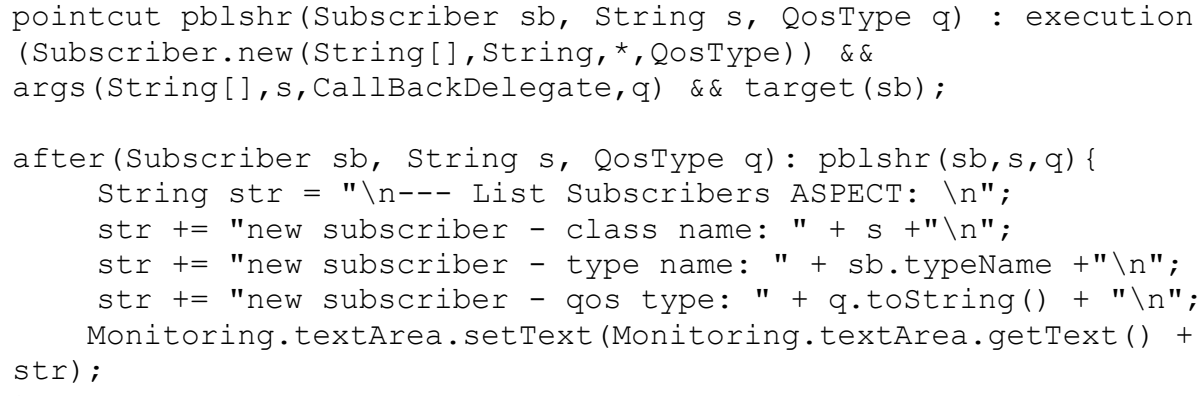

Şekil 5. Abone Listele (ListsSubscribers) İlgisi

- Abone Listele (ListsSubscribers) İlgisi: ListSubscribers ilgisi ile DDS tabanlı bir sistemdeki aboneler ve özellikleri izlenebilir. $\mathrm{Bu}$ ilgi için geliștirilen pointcut ve tavsiye (advice) Şekil-5'de verilmiștir.

- Yayıncı Listele (ListPublishers) İlgisi: ListPublisher ilgisi kullanılarak, DDS tabanlı bir sistemdeki yayıncılar ve özellikleri listelenebilir. DDS'de yayıncı ve abone tanımlamaları farklı olduğu için, yayıncı izleme ilgisi yukarıda verilen abone izleme ilgisinden farklıdır (Sekil6).

- Abone Olunan Veri Tipini Al (GetTypeOfSubcribedData) İlgisi: Abone olunan verinin tipinin ve gelen veri değerlerinin izlenmesi bu ilgi ile sağlanmaktadır Bu ilgide, abone olunan verinin sınıfı, özellikleri ve değerleri izlenmektedir. $\mathrm{Bu}$ ilgi, yanlıș veri ayarlarından kaynaklanan hataların ayrıştırılmasında önemli rol oynamaktadır. $\mathrm{Bu}$ ilgi için geliştirilen pointcut ve tavsiye Şekil-7'de verilmiștir.
- Abone Olunan Veri Tipini Al (GetTypeOfSubcribedData) İlgisi: Abone olunan verinin tipinin ve gelen veri değerlerinin izlenmesi bu ilgi ile sağlanmaktadır $\mathrm{Bu}$ ilgide, abone olunan verinin sınıfı, özellikleri ve değerleri izlenmektedir. $\mathrm{Bu}$ ilgi, yanlış veri ayarlarından kaynaklanan hataların ayrıştırılmasında önemli rol oynamaktadır. Bu ilgi için geliștirilen pointcut ve tavsiye Şekil-7'de verilmiștir.

\section{- Yayınlanan Veri Tipini Al (GetTypeOfPublishedData) İlgisi: Yukarıda belirtilen GetTypeOfSubscribedData ilgisine} benzer şekilde tasarlanmıştır. Bu ilgi, yayınlanan verinin ismini, sınıfını, tipini ve değerlerini izlemek için tasarlanmıştır. Özellikle yazılım geliştirme ve test aşamalarında sıklıkla ihtiyaç duyulan GetTypeOfPublishedData ilgisinin kodları Şekil-8'de belirtilmiştir. 
Ö. Köksal ve M. Akyüz / Veri Dağıtım Servisi Tabanlı Sistemlerde Enine Kesen İlgiler İçin İlgiye Yönelik Programlama Yaklașımı

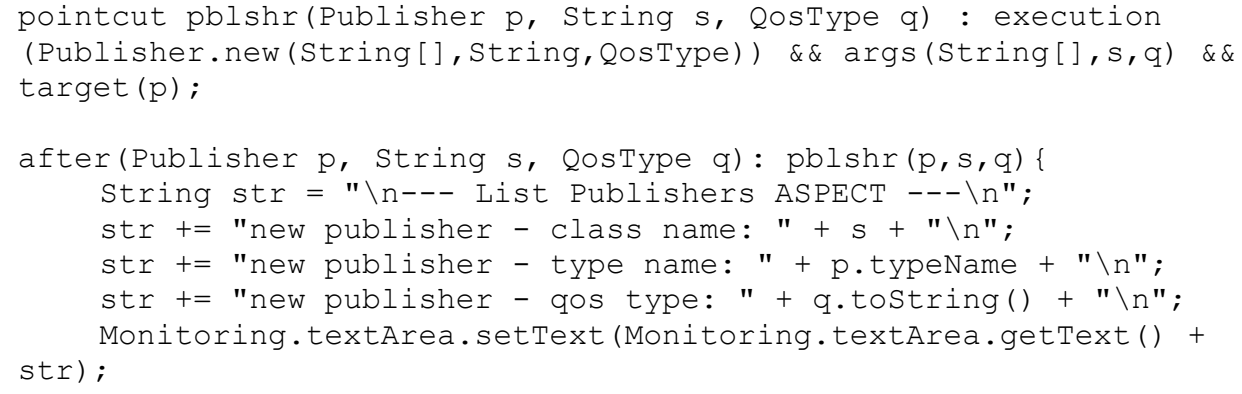

Şekil 6. Yayıncı Listele (ListPublisher) İlgisi

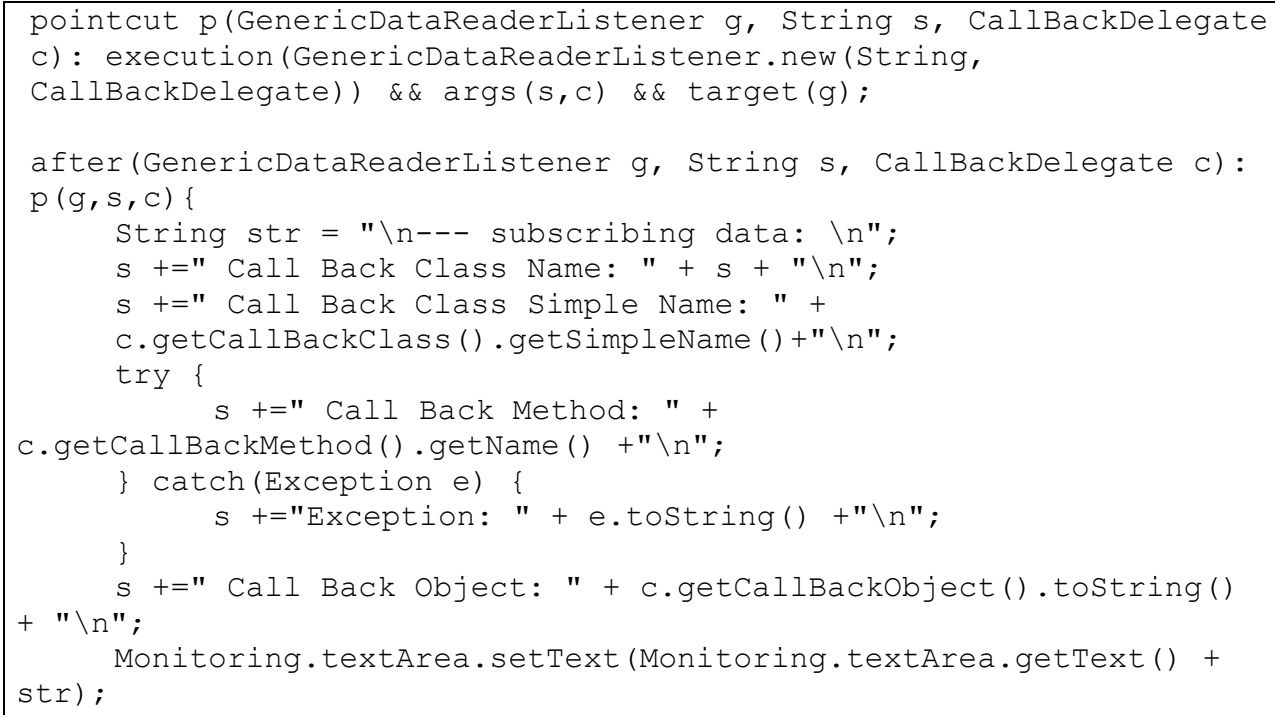

Şekil 7. Abone Olunan Verinin Tipini Al (GetTypeOfSubscribedData) İlgisi

\subsection{Servis Kalitesi Uygulama (Enforce} QoS) İlgisi

Bölüm 2.3'de belirtildiği gibi, DDS tabanlı sistemlerde, yayıncl, abone ve konu için tanımlanmış olan QoS parametreleri uyumsuzsa veri alış-verişi gerçekleşmez. Böyle bir durumun tespit edilmesi, geleneksel yazılım geliștirme yöntemleri ile bir hayli zordur. Bu nedenle, aynı konu üzerinden haberleşmeleri istenen yayınciların ve abonelerin QoS değerlerinin izlenmesi, gerekirse değiştirilmesi, DDS tabanlı sistemlerin geliștirilmesinde önemlidir. $\mathrm{Bu}$ amaçla geliştirilen EnforceQoS ilgisi, yayıncı ve abonenin QoS parametrelerinin izlenmesini sağlar. QoS parametrelerinin dinamik olarak nasıl değiștirilebileceğini göstermek için EnforceQoS ilgisi, örnek uygulamamız C2S'de haberleşme için ihtiyaç duyulan Reliable QoS parametresi içim geliştirilmiștir. EnforceQoS ilgisi, QoS değerinin Reliable olarak tanıml olup olmadığını kontrol eder, bu șekilde tanımlı değilse uyarı mesajı tanımlayarak QoS değerini Reliable yapar. EnforceQoS ilgisinin pointcut ve tavsiyeleri Şekil 9'da verilmiștir. 
Ö. Köksal ve M. Akyüz / Veri Dağıtım Servisi Tabanlı Sistemlerde Enine Kesen İlgiler İçin İlgiye Yönelik Programlama Yaklaşımı

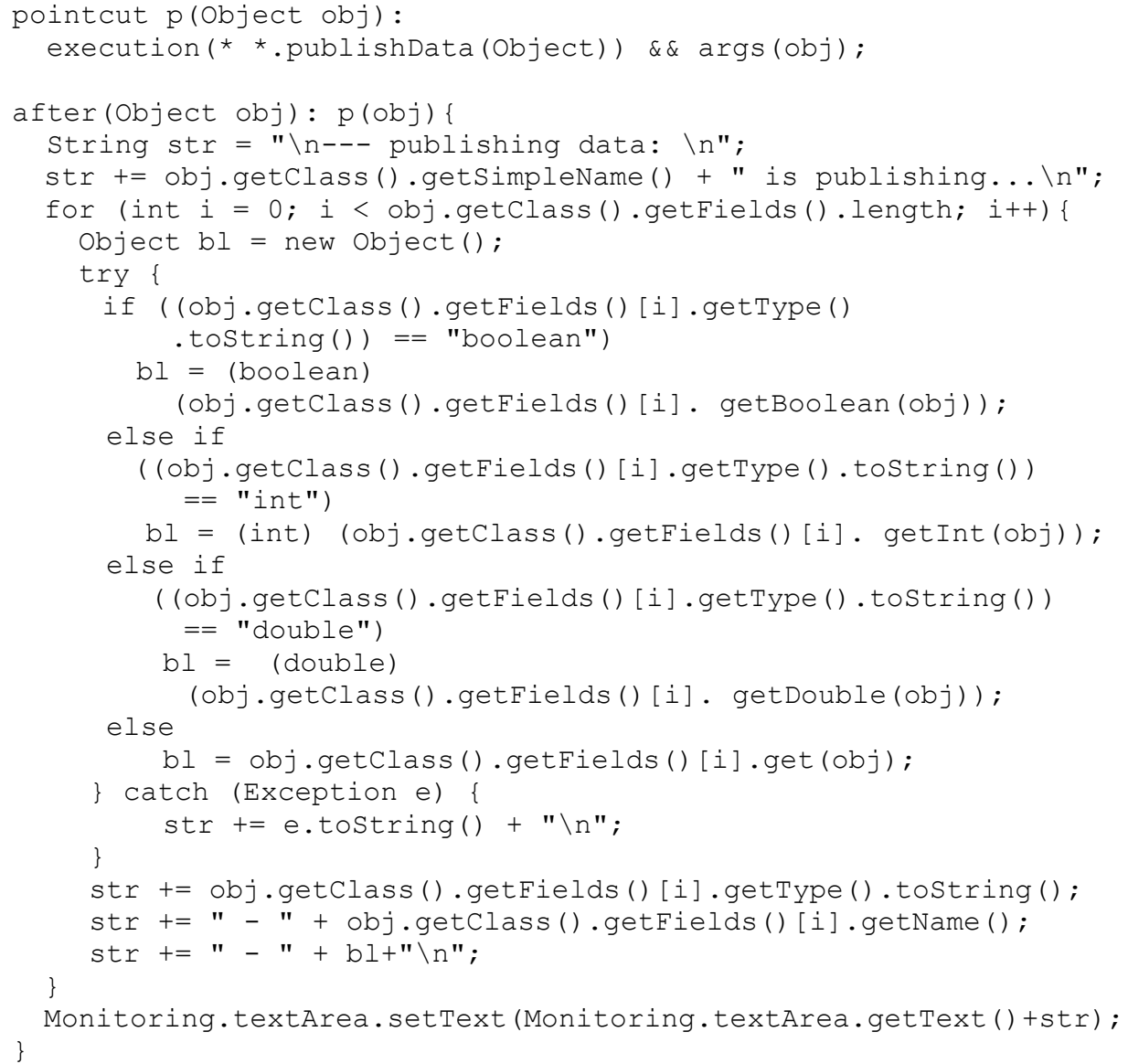

Şekil 8. Yayınlanan an Veri Tipini Al (GetTypeOfPublishedData) İlgisi

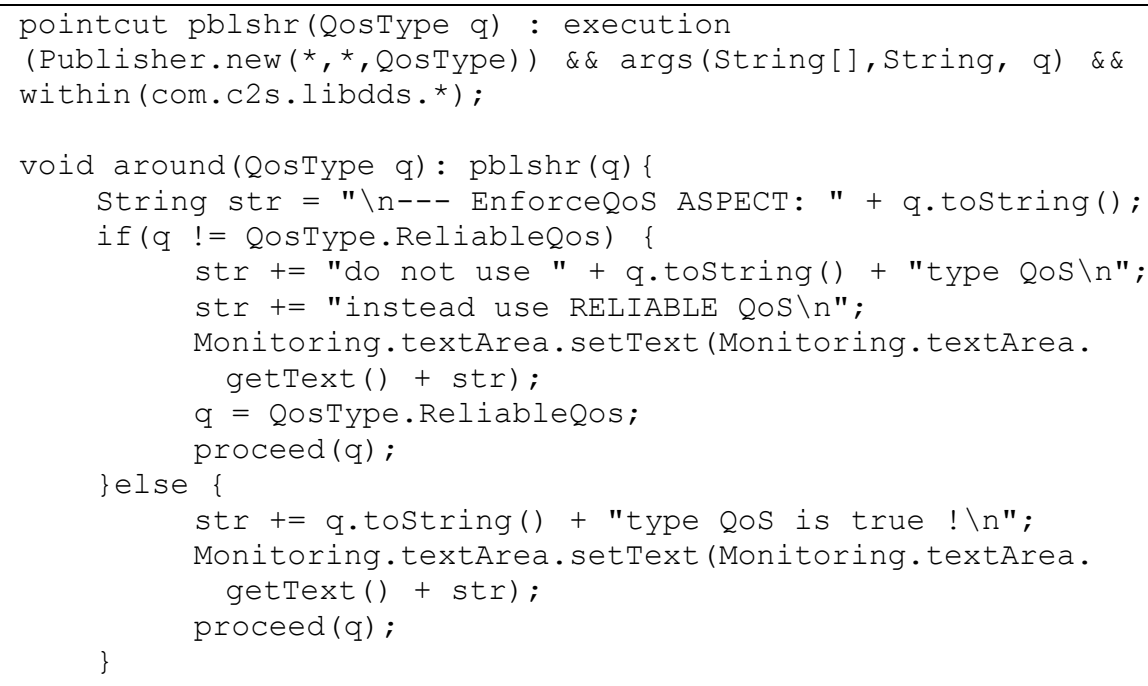

Şekil 9. Servis Kalitesi Uygulama (EnforceQoS) İlgisi 
Ö. Köksal ve M. Akyüz / Veri Dağıtım Servisi Tabanlı Sistemlerde Enine Kesen İlgiler İçin İlgiye Yönelik Programlama Yaklaşımı

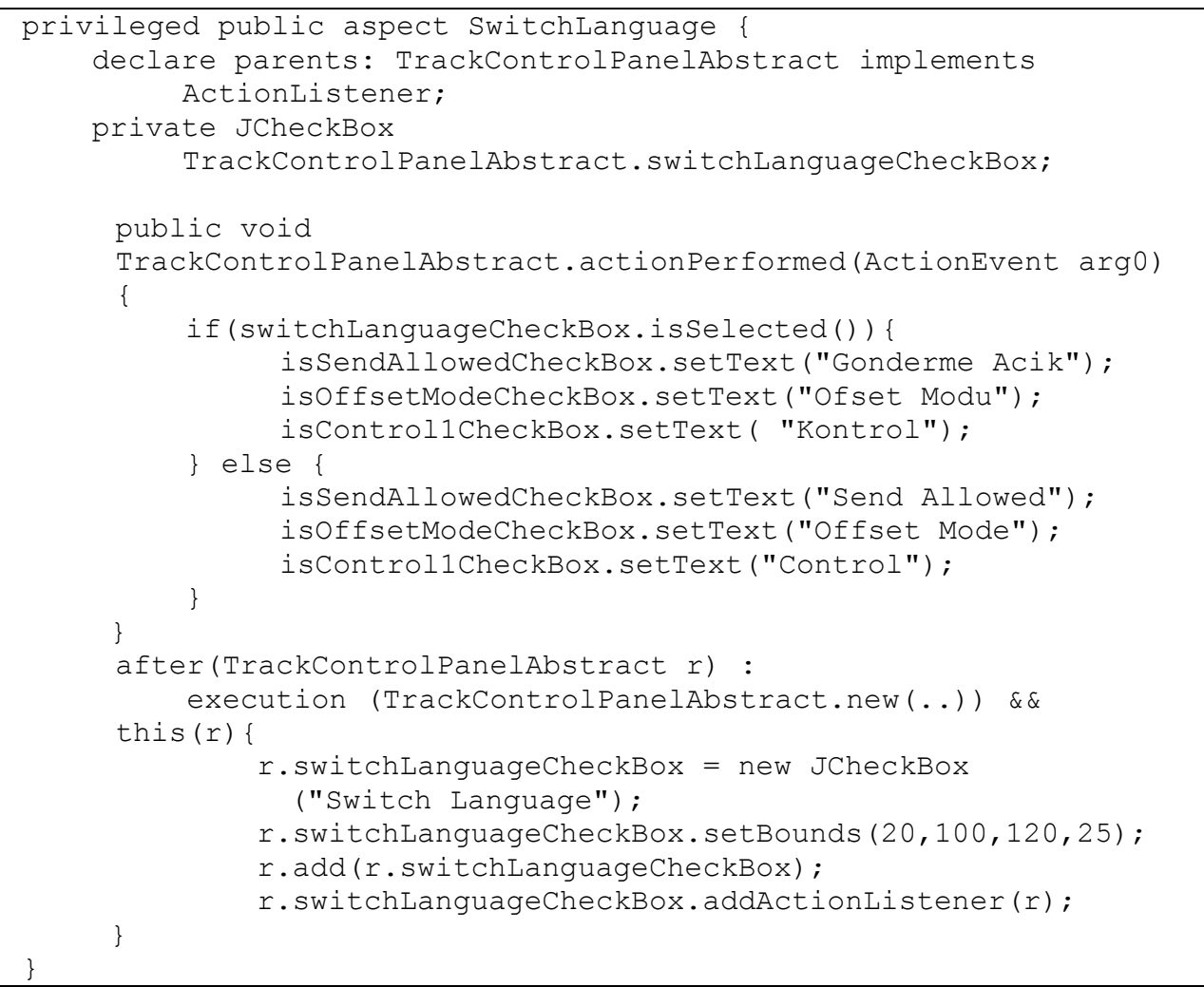

Şekil 10. Dil Değişim (SwitchingLanguage) İlgisi

\subsection{Dil Değişim (SwithcingLanguage)} İlgisi

DDS tabanlı bir komuta kontrol programı kullanıcı arayüzünde ya da veri kayıt/saklama işlemlerinde farklı dillerde çalışmayı desteklemelidir. Özellikle kalıt kodların (legacy code) kullanıldığı bir geliştirme ortamında, kullanıcı arayüzündeki bileşenlere erișerek faklı dil desteği sağlamak büyük kod değişiklikleri ve zaman gerektirir.

Örnek C2S uygulamasında geliştirdiğimiz, dil değișim ilgisi ile DDS tabanlı sistemlerde çoklu dil desteğinin nasıl sağlanacağı gösterilmiştir. Dil değişim ilgisi, kullanıcı arayüzündeki etiketlerin, istenilen dilde gösterilmesini sağlar. $\mathrm{Bu}$ ilgi, mevcut kodlarda değişiklik yapmayı gerektirmediği için kolaylıkla kalıt kodlara da uyarlanabilir. Dil değişim ilgisinin pointcut ve tavsiyeleri Șekil-10'da verilmiștir.

\section{3. İlgili Çalışmalar}

Yazılımların modüler olarak geliştirilebilmesi, yeniden kullanım oranının artırılabilmesi, yönetim ve bakım çalışmalarının daha kolay yürütülebilmesi için Eric Gamma ve arkadaşları 1993'te [18], Buschmann ve arkadaşları 1996'da [11] yazılım tasarım örüntülerinin uygulanmasını önermişlerdir. Bütün bu faydalarına rağmen, yazılım örüntülerinin kullanılması, yazılımlardaki enine kesen ilgi problemlerini engelleyememektedir.

Nesneye yönelik programlama ile geliştirilen yazılımlardaki enine kesen ilgi problemlerinin çözümü için 1997'de Kiczales, "İlgiye Yönelik Programlama (Aspect Oriented Programming)" metodolojisini ortaya koymuştur [19]. Ancak bu çözümde, yazılım örüntüleri 
gibi jenerik bir çözümdür ve doğrudan dağıtık sistemlerle ve DDS ile ilgili çözümler içermemektedir. Bu çalışmada ise özellikle DDS tabanlı sistemlerdeki enine kesen ilgi problemlerine odaklanılmıştır.

DDS arakatmanı geliştiren firmalar, yazılım ve test mühendislerine yardımcı olacak bazı geliştirme araçlarını da kendi ürünleri ile birlikte sunmaktadırlar. Object Computing Inc. (OCI) firmasının [20] geliştirdiği, OpenDDS [4] yazılımı ile birlikte sunulan DDS Monitoring Tool, Real Time Innovations (RTI) firmasının [15] geliștirdiği Connext DDS yazılımı ile birlikte sunulan SPY, PrismTech firması [16] tarafından geliştirilen Vortex yazılımı ile birlikte sunulan Tester, Tuner, Configurator yazılımları, milli DDS üreten MilSOFT firmasının geliștirdiği MilSOFT DDS yazılımı ile birlikte sunulan MilSOFT SPY yazılımı bu araçlara örnek olarak verilebilir. Bu araçlar sadece kendi firmalarının yazılımları ile çalışmaktadırlar. Yani, bu araçlar ile geliştirilmiş herhangi bir çözümün, diğer bir DDS üreticisinin kodlarına taşınması ve uygulanması mümkün değildir. Enine kesen ilgilere odaklanmış araçlar değillerdir, genelde izleme (monitoring) ve hızlı yazılım geliştirme amaçlı tasarlanmışlardır.

$\mathrm{Bu}$ makale, ön çalışma olarak gerçekleştirdiğimiz ilgiye yönelik programlama aracı [21] çalışmasının devamı olarak gerçekleştirilmiştir. Bu makalede, ön çalışmanın üzerinde ilerleyerek, DDS tabanlı sistemlerdeki, enine kesen ilgilere odaklanılmış ve ilgiye yönelik programlama yaklaşımının DDS tabanlı sistemler için kullanımı detaylandırılmıştır.

\section{Bulgular ve Sonuçlar}

Dağıtık sistemlerin geliştirilmesi uzun ve zorlu bir süreçtir. Bu süreçte pek çok yazılım ve test mühendisinin birlikte

\begin{abstract}
çalışarak proje ihtiyaçlarını gerçeklemesi gerekmektedir. DDS arakatmanı, dağıtık sistemler geliştirmek için son yıllarda yaygın olarak kullanılan açık standartlı ve gerçek zamanlı bir arakatman yazılımıdır. Dağıtık sistem geliștirmek için sağladığı güçlü mekanizmalara rağmen enine kesen ilgi problemleri DDS arakatmanının tasarımında çok fazla düşünülmüş bir konu değildir.
\end{abstract}

Bu makalede, veri dağıtım servisi (Data Distribution Service - DDS) tabanlı dağıtık sistemlerdeki enine kesen ilgilere çözüm üretebilmek için, ilgiye yönelik programlama (Aspect Oriented Programming - AOP) yaklaşımı anlatıldı. Öncelikle, DDS arakatmanının temel haberleşme mekanizması olarak kullandığı yayınla-abone ol (publishsubscribe) mimarisi ve servis kalitesi parametreleri (Quality of Service - QoS) hakkında temel bilgiler verildi.

İlgiye yönelik programlama yaklaşımının DDS tabanlı sistemlerde kullanımını detaylandırabilmek için, savunma sanayimizdeki pek çok projede geliştirmekte olduğumuz komuta kontrol sistemlerini temsil eden bir mini komuta kontrol sistemi (Command and Control System - C2S) örnek çalışma olarak kodlandı.

Nesneye yönelik programlama (Object Oriented Programming - OOP) ile geliştirilen C2S içindeki enine kesen ilgilerden örnekler verildi. $\mathrm{Bu}$ enine kesen ilgilerden, makale kapsamında sadece DDS arakatmanı ile ilgili 3 adet ilgiye odaklanıldı. Nesneye yönelik programlamanın ve kullanılan DDS arakatmanının, modüler ve ölçeklenebilir yazılım geliştirme için sağladığı güçlü mekanizmalara rağmen, enine kesen ilgiler için çabuk çözümler üretemediği görüldü. Diğer taraftan, ilgiye yönelik programlama yaklaşımı ile mevcut kodları değiștirmeden hızlı ve 
faydalı çözümler üretilebileceği gösterildi. Belirlenen 3 adet ilgi için, C2S üzerinde kodlanan ilgiler detaylandırıldı ve AspectJ ile geliştirilen kodları verildi.

Aynı sonuçları, sadece nesneye yönelik programlama ile elde etmek için büyük kod değişiklikleri gerekirken, ilgiye yönelik programlama da kodları hiç değiștirmeden, sadece basit ilgiler geliştirerek faydalı çözümler üretilebileceği vurgulandı. Bu ilgilerin kalıt kodlara (legacy code) da kolaylıkla uyarlanabileceği belirtildi. Bu kapsamda geliştirilen ilgiler, DDS tabanlı dağıtık sistemler geliştirmede yazılım ve test mühendislerinin ișlerini kolaylaştırmakta ve ürün geliştirme süresini azaltmaktadır.

Burada not edilmesi gereken başka bir konu da ilgiye yönelik programlama için kullanılabilecek, pek çok açık kaynaklı ve ücretsiz kütüphane ve derleyicinin bulunmasıdır. $\mathrm{Bu}$ kütüphane ve derleyicilerin yardımı ile kolaylıkla geliştirilebilecek ilgiler ile kısa sürede faydalı sonuçlar elde etmek mümkündür. Alternatif olarak kullanılabilecek olan DDS üretici firmaların geliştirme araçlarının pek çoğu açık kaynak kodlu değildir ve oldukça yüksek maliyetlidir.

İlgiye yönelik programlamanın yukarıda belirtilen faydalarına rağmen, performans problemlerine yol açabileceği not edilmelidir. Çünkü ilgiye yönelik programlama araçları / kütüphaneleri, ilgilerin gerçekleştirmesinde yansıma (reflection) mekanizmaları kullanırlar. $\mathrm{Bu}$, sistem performansını etkileyen bir yaklaşımdır. İlgiye yönelik programlama, sorun çözme ve test amaçlı kullanımda ideal olmasına rağmen, son ürünlerin içinde yer alması gerektiğinde performans problemlerini göz önünde bulundurmanın ve detaylı performans testleri yapmanın önemli olduğu düşünülmektedir.

$\mathrm{Bu}$ çalışma kapsamında geliștirilen örnek ilgilerin daha büyük DDS tabanlı sistemlerde, aynen ya da küçük değişiklerle kullanılabileceği, eklenmesi düşünülen yeni ilgiler için örnek teşkil edebileceği düșünülmektedir. $\mathrm{Bu}$ şekilde, DDS tabanlı dağıtık sistem geliştiren yazılım ve test mühendislerine kolaylı ve zaman tasarrufu değerlendirilmektedir.

\section{Teşekkür}

$\mathrm{Bu}$ çalıșmanın tamamlanmasındaki tüm katkıları için Prof. Dr. Bedir Tekinerdoğan'a (Wageningen Üniversitesi, Hollanda) teşekkür ederiz.

\section{Kaynakça}

[1] Castellote G.P., Farabaugh B. 2005. An Introduction to DDS and DataCentric Communications: Teknik Rapor, Real Time Innovations.

[2] Köksal Ö. 2008. DDS Arakatmanı Nedir?: Teknik Rapor, ASELSAN.

[3] Köksal Ö., Bozkurt A. 2009. DDS Arakatmanı Çalışma Prensipleri: Teknik Rapor, ASELSAN.

[4] OpenDDS. http://www.opendds.org (Erişim Tarihi: 01.08.2016).

[5] Aspect]: http://eclipse.org/aspectj (Erişim Tarihi: 01.08.2016).

[6] AspectJ Programlama Klavuzu: http://www.eclipse.org/aspectj/do c/released/progguide/index.html (Erişim Tarihi: 01.08.2016).

[7] Eclipse: http://eclipse.org (Erişim Tarihi: 01.08.2016).

[8] Schmidt D.C., Corsaro A. ve Hag H.V. 2008. Addressing the Challenges of Tactical Information Management in Net-Centric Systems with DDS: The Journal of Defense Software Engineering, S. 24-29.

[9] Corsaro A. 2012. Quality of Service in Publish/Subscribe Middleware: 
Ö. Köksal ve M. Akyüz / Veri Dağıtım Servisi Tabanlı Sistemlerde Enine Kesen İlgiler İçin İlgiye Yönelik Programlama Yaklaşımı

Emerging Communication, Cilt. 8, s. 79-97.

[10] Ryll M., Ratchev S. 2008. Towards a publish / subscribe control architecture for precision assembly with the Data Distribution Service: IFIP International Federation for Information Processing, Cilt. 260, s. 359-369.

[11] Buschmann, F., Meunier R., Rohnert, H., Sommerlad, P. ve Stal, M. 1996. Pattern-Oriented Software Architecture: A System of Patterns, Cilt. 1, s. : 476.

[12] Object Management Group: http://www.omg.org (Erișim Tarihi: 01.08.2016).

[13] Data Distribution Service: http://www.omg.org/spec/DDS

(Erişim Tarihi: 01.08.2016).

[14] MilSOFT DDS,

http://dds.milsoft.com.tr (Erişim Tarihi: 01.08.2016).

[15] Real Time Innovations DDS, https://www.rti.com/products (Erișim Tarihi: 01.08.2016).

[16] PrismTech, http://www.prismtech.com/vortex (Erişim Tarihi: 01.08.2016).

[17] Arayüz Tanımlama Dili (Interface Definition Language-IDL), http://www.omg.org/gettingstarte d/omg_idl.htm (Erişim Tarihi: 01.08.2016).

[18] Gamma E., Helm R., Johnson R. E., ve Vlissides J. M. 1993. Design Patterns: Abstraction and Reuse of Object-Oriented Design: Proceedings of the 7th European Conference on Object Oriented Programming, s. 406-431.

[19] Kiczales G. 1996. Aspect Oriented Programming: ACM Computing Surveys, Cilt. 154, s. 28.

[20] Object Computing INC, http://www.ociweb.com

(Erişim Tarihi: 01.08.2016).

[21] Köksal Ö. ve Akyüz M. 2011. Aspect Oriented Development Tool To Support Implementation of DDS
Based Systems: Sunum, Fifth Turkish Aspect-Oriented Software Development Workshop.

[22] Common Object Request Broker Architecture (CORBA): http://www.omg.org/spec/CORBA (Erişim Tarihi: 01.08.2016). 